\title{
Relationship between Foot Position and Lumbar Loads while Turning Patients on a Bed: An Investigation via Computational Simulation and Electromyography
}

\author{
https://doi.org/10.3991/ijoe.v17i10.25161 \\ Kodai Kitagawa $^{(\varpi)}$, Kotaro Yamamoto, Chikamune Wada \\ Kyushu Institute of Technology, Kitakyushu, Japan \\ Kitagawakitagawa156@gmail.com
}

\begin{abstract}
Caregivers have lower back pain (LBP) since they must reposition patients in bed frequently. Thus, the low lumbar load posture for turning patients should be explored. In this study, we focused on foot position because it can be easily adjusted to reduce back pain. The hypothesis was that short anteroposterior foot distance could reduce lumbar loads because closer position to patient made smaller moments. Therefore, this study aimed to investigate the relationship between foot position and lumbar loads while turning patients on beds. Furthermore, we compared compression stresses of L4-L5 via computational simulation and erector spinae muscle activities obtained from electromyography (EMG) in nine foot positions. The results showed that short anteroposterior foot distance reduced lumbar loads while turning a patient on a bed.
\end{abstract}

Keywords_-caregiver, patient handling, foot position, lumbar load.

\section{$1 \quad$ Introduction}

Caregivers have lower back pain (LBP) due when handling patients while providing care [1]-[4]. Particularly, turning a patient on a bed causes LBP because this motion is frequently performed to reposition a patient on a bed [5]. Thus, the low load posture and movement for turning a patient should be investigated to prevent LBP among caregivers. In the literature, several previous studies investigated postures, movement, and devices to reduce the lumbar load during patient handling [6]-[10]. These studies found that assistive devices such as sliding sheets could reduce lumbar loads during patient handling [6]. Additionally, turn-assist devices could reduce the caregiver's load when repositioning a patient on a bed $[9,10]$. However, these assistive devices were not used in several workspaces because caregivers require timeefficient, comfortable, and cost effective devices [11].

Body mechanics-based patient handling could reduce lumbar loads without using assistive devices [7, 8]. Body mechanics provides several strategies, such as moving the center of gravity closer to the patient, to reduce lumbar loads [7]. However, there are no definitive postural parameters to realize these strategies. Thus, effective parameters and thresholds should be investigated to optimize body-mechanics-based 
patient handling. Posture adjustment using a wearable feedback system has been useful for reducing lumbar loads [12]. Doss et al. could improve posture and movement of nursing students during patient handling by intervention including wearable feedback system for spine angle [12]. This wearable feedback system is monitoring and giving feedback on spine angle through inertial sensors [12]. Although their intervention required verbal coaching about lower limb postures [12], this study indicates that threshold and feedback for parameters related to lower limbs are necessary for providing low load patient handling.

From these backgrounds, we are focusing on foot position as an effective parameter to reduce lumbar loads during patient handling since foot position can be adjusted easily in initial posture $[13,14]$. Our previous study found that the foot position with a wide stance (anteroposterior 55\% and mediolateral $20 \%$ of body height) can reduce lumbar loads during patient handling for sit-to-stand movement [14]. However, a suitable foot position for turning a patient on a bed has not been investigated.

This study investigates the relationship between foot position and lumbar loads in turning patients on a bed. Moving the center of gravity closer to the patient is an effective strategy to reduce lumbar loads because the shorter distance concluded smaller moments on the lumbar [7]. Thus, this study hypothesized that short anteroposterior foot distance could reduce lumbar loads due to closeness to the patient.

The rest of the paper is organized as follows. Section 2 introduces an experimental method to investigate the relationship between foot position and lumbar load while turning a patient on a bed. Section 3 presents experimental results. Section 4 presents discussions for this study. Finally, the conclusions of this paper are presented in Section 5 .

\section{Method}

\subsection{Participants}

The study included four young, healthy male participants as simulated caregivers (age, $23.0 \pm 0.700$ years; body height, $1.74 \pm 0.04 \mathrm{~m}$; body weight, $61.4 \pm 3.00 \mathrm{~kg}$ ) and a healthy male participant as a simulated patient (age, 22.0 years; body height, $1.62 \mathrm{~m}$; body weight, $58.3 \mathrm{~kg}$ ). The participants had no experience in care activities that include patient handling. All participants provided verbal informed consent before the experiment.

\subsection{Materials}

Computational simulation and electromyography (EMG) were used to investigate the relationship between foot position and lumbar loads.

A computational simulation was used to investigate the compression stress of lumbar vertebrae (L4-L5). Compression stress of L4-L5 is an important factor as lumbar load because compression stress of vertebral causes serious injuries such as hernia [15]-[17]. However, directly measuring the compression stress of L4-L5 is difficult. 
Thus, the compression stress of L4-L5 based on the caregiver's posture was estimated using the 3D Static Strength Prediction Program (3DSSPP, University of Michigan, USA). The 3DSSPP can estimate the compression stress of L4-L5 during manual handling by Bean et al.'s musculoskeletal model [18, 19]. A previous study reported that the 3DSSPP could accurately estimate the compression stress of L4-L5 during manual handling with various postures such as asymmetry and standing postures; thus, the 3DSSPP was selected for computational simulation [19]. Furthermore, in many previous studies, the 3DSSPP was used to evaluate lumbar loads during patient handling [20]-[22].

A digital camera (LUMIX, Panasonic Co., Japan) and the Kinovea (Joan Charmant $\&$ Contrib, France) were used to measure the positions and angles of body segments for the input of the 3DSSPP. The Kinovea can calculate kinematic values such as joint angle from 2D movies and images [23]-[26]. Since the Kinovea had been validated for measuring kinematic values in various fields such as clinical and sports biomechanics, it was selected as the motion analysis software [23]-[26].

The erector spinae muscle activity was evaluated using surface electromyography (sEMG). Previous studies indicated that increasing the erector spinae muscle activity caused LBP; thus, it was investigated as lumbar loads [27]-[30]. Furthermore, Callaghan et al. reported that erector spinae muscle activity increased with spine load during trunk movement [28]. The electrode positions for repeatable measurement were clarified in a previous study; thus, the sEMG was selected for evaluating the erector spinae muscle activity [31].

\subsection{Experimental procedure}

The caregivers performed turning a patient on the bed (width, $0.95 \mathrm{~m}$; length, 2.00 $\mathrm{m}$; height, $0.88 \mathrm{~m}$ ) in nine foot positions with different foot distances. Based on previous studies, the size and height of the bed were determined [32, 33]. Figure 1 shows the movement of turning a patient on a bed. The caregivers turned a patient from supine to lateral position on the bed. The nine foot positions are shown in Figure 2. The nine foot positions had different foot distances normalized by body height (unit, \%height). The range of foot distance was defined to keep subjective comfortability for patient handling among all caregivers. The right foot was placed in front of and near the patient's hip. Turning the patient was repeated five times for each foot position. The order of foot position was randomized for each caregiver. 


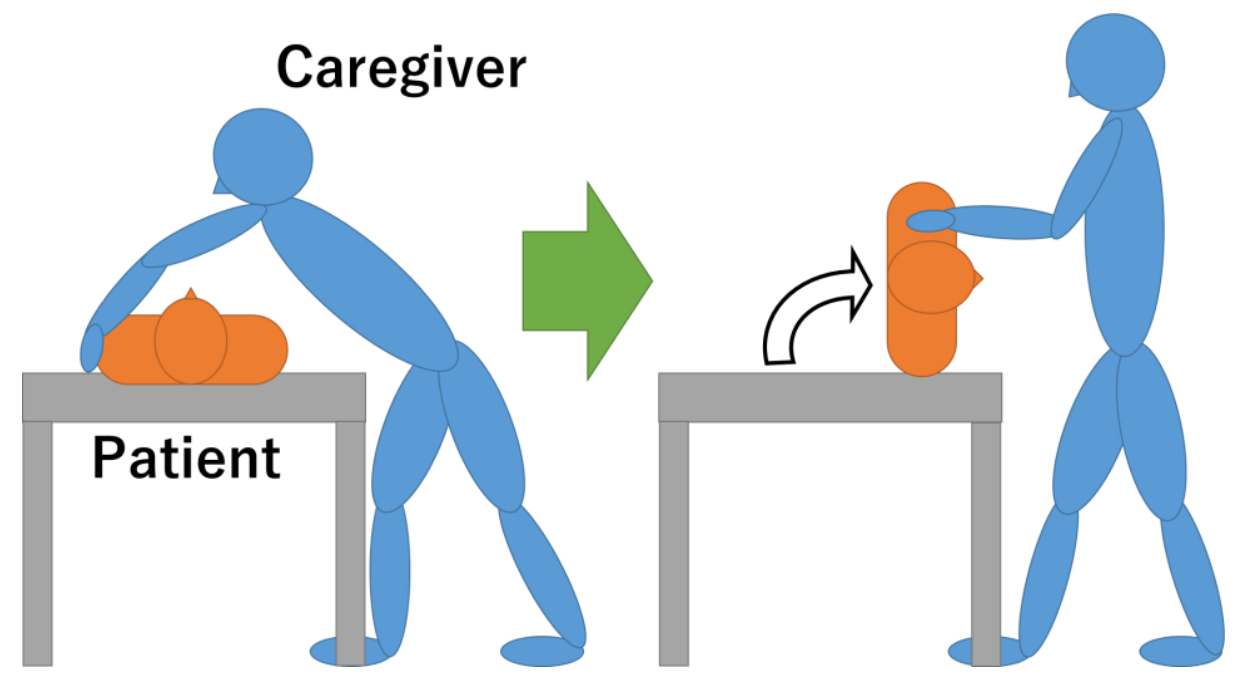

Fig. 1. Turning patient on a bed

\section{$40 \% 30 \% 20 \%$}
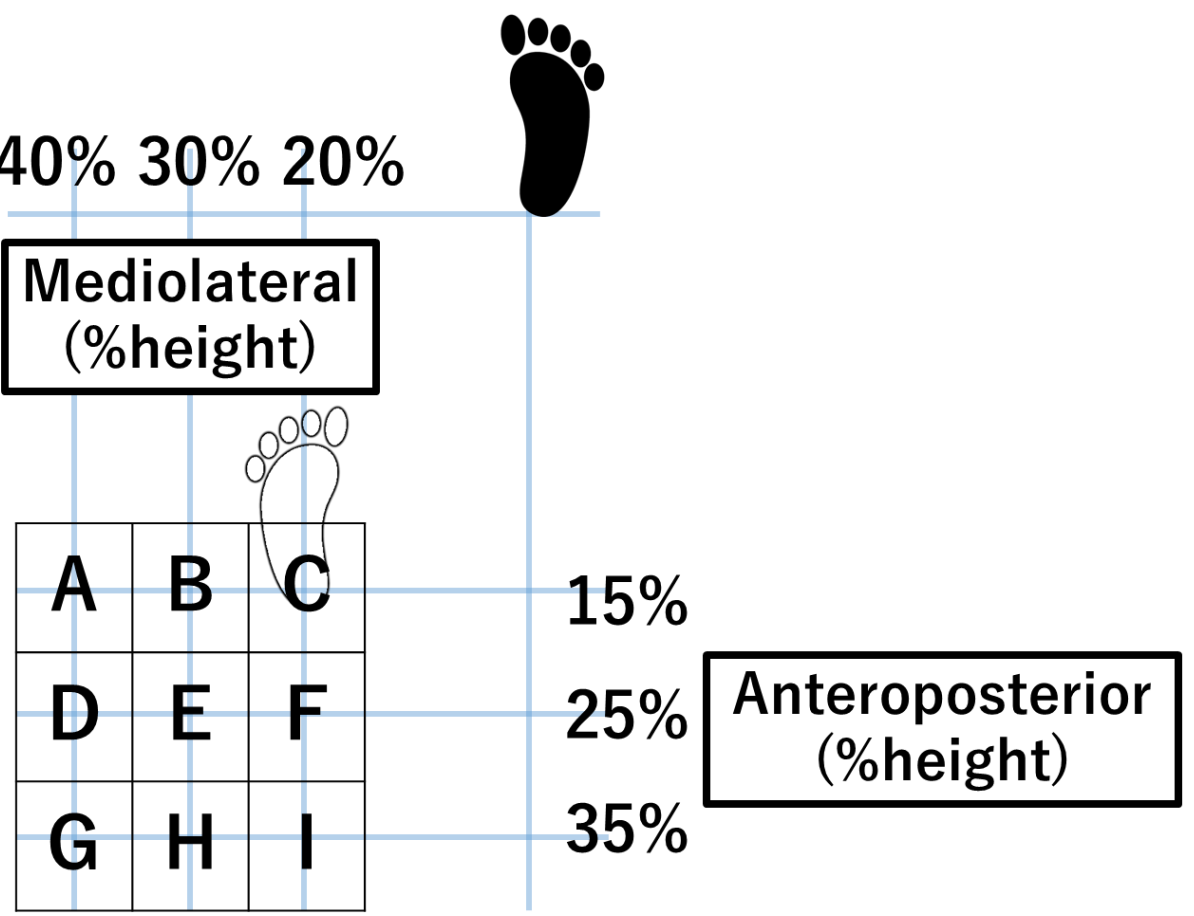

Fig. 2. Nine foot positions in turning patient

The turning patient motions performed by one of the four simulated caregivers (age, 22.0 years; body height, $1.74 \mathrm{~m}$; body weight, $59.2 \mathrm{~kg}$ ) were recorded using a digital camera for computational simulation. Furthermore, the joint angles and posi- 
tions on the sagittal plane of each motion were calculated by Kinovea. These joint angles and positions were input into the 3DSSPP. Figure 3 shows the simulation model of 3DSSPP for turning a patient on a bed. Instead, of a patient, loads equal to the patient's body weight were applied on both hands of the caregiver. The compression stress of L4-L5 for each motion was calculated using the 3DSSPP with a $25 \mathrm{~Hz}$ sampling frequency. Mean and maximum values of the compression stress of L4-L5 for each trial were calculated for comparison. Furthermore, the distance between the center of mass of caregiver and patient in initial posture was calculated for each foot position. We calculated these distances to verify our hypothesis that short foot distance could reduce lumbar loads due to closeness to the patient.

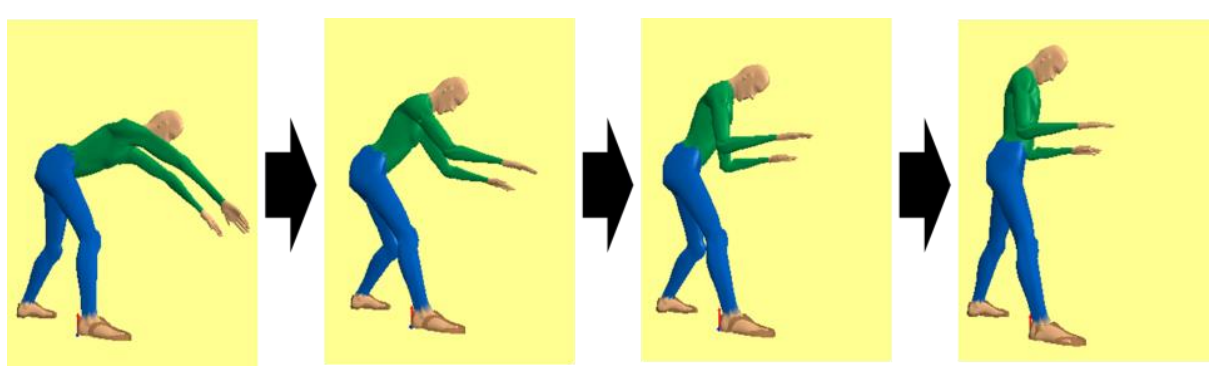

Fig. 3. Turning patient on a bed in the 3DSSPP

The sEMGs of left and right erector spinae muscles were measured for all trials and caregivers. Blue Sensor P (Ambu, Ballerup, Denmark) and the EMG Logger (LPWS1402-W, Logical Product Inc., Fukuoka, Japan) were used to measure the sEMG with $1 \mathrm{kHz}$ sampling frequency. The electrode position was based on McGill's investigation [31]. The sEMG values were normalized by maximal voluntary contractions based on Daniels and Worthingham's muscle test (unit, \%MVC) [34]. Integrated EMG (iEMG) values were calculated from the rectified signal of sEMG. The iEMG values were normalized temporally by total motion time for each trial. This signal processing was performed by MATLAB R2020b (MathWorks Inc., USA).

\subsection{Statistical analysis}

Spearman's rank correlations between the maximum compression stress of L4-L5 and distance between caregiver and patient were calculated (significant level, $p<$ 0.05). The Kruskal-Wallis test and Bonferroni method were used to compare the iEMG values of left and right erector spinae muscles of the nine foot positions (significant level, $p<0.05$ ). These statistical tests were performed by EZR (Kanda, Japan) [35]. 


\section{Results}

Figure 4 shows the temporal waveforms of compression stress of L4-L5. The maximum compression forces were in the initial posture for all foot positions. Figure 5 shows the compression stress of L4-L5 and also the injury threshold (3400 N) defined by the National Institute of Occupational Safety and Health (NIOSH) [36]. The results revealed that the compression stress of L4-L5 in foot positions A, B, and C with short anteroposterior foot distance were less than $3400 \mathrm{~N}$, and the maximum compression stresses of L4-L5 were more than $3400 \mathrm{~N}$ in other foot positions. Figure 6 shows distances between the center of mass of caregiver and patient in the initial posture of the nine foot positions. The distances of foot positions A, B, and C with small compression stress of L4-L5 were shorter than those of other foot positions. In addition, there was a significant correlation between the maximum compression stress of L4L5 and distance $(r=0.917 ; p<0.05)$.

Figures 7 and 8 show left and right erector spinae muscle activity in nine foot positions. In both left and right erector spinae muscles, no significant difference was observed for all foot positions $(p>0.05)$.

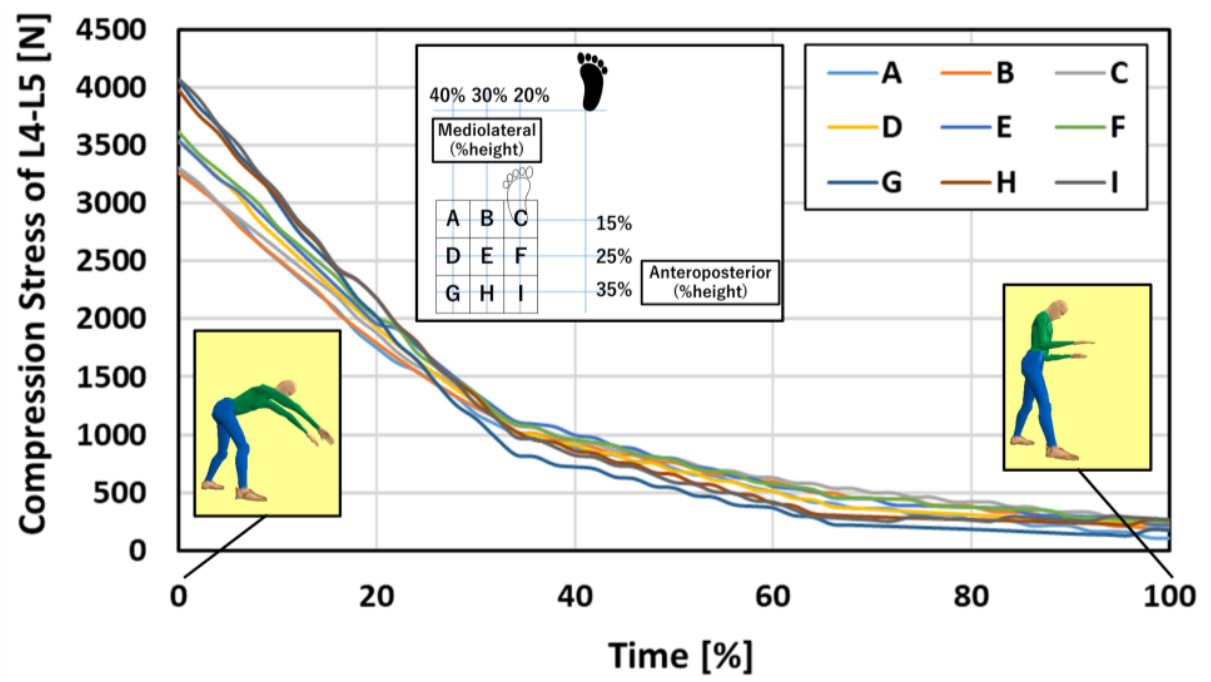

Fig. 4. Temporal waveforms of compression stress of L4-L5 

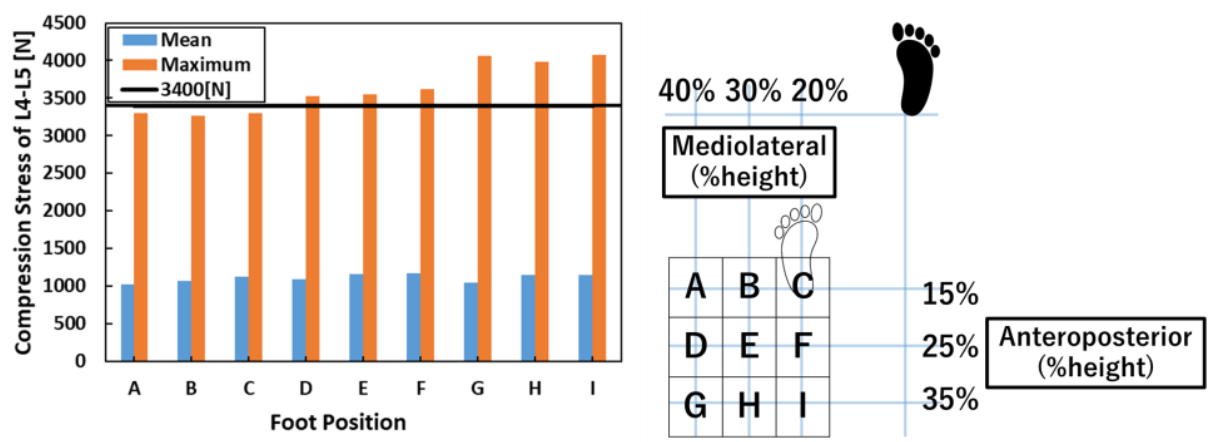

Fig. 5. Compression stresses of L4-L5 in nine foot positions

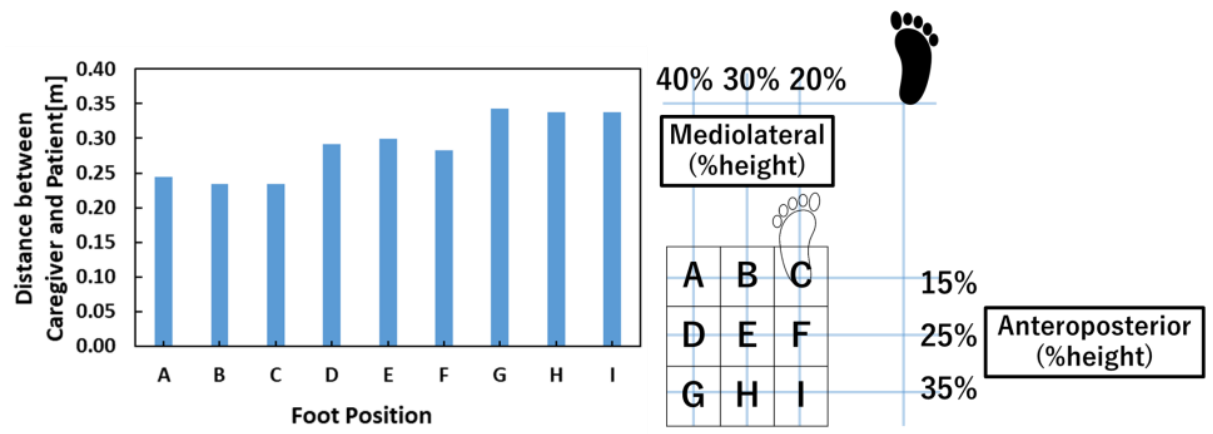

Fig. 6. Distance between caregiver and patient in the initial posture of nine foot positions

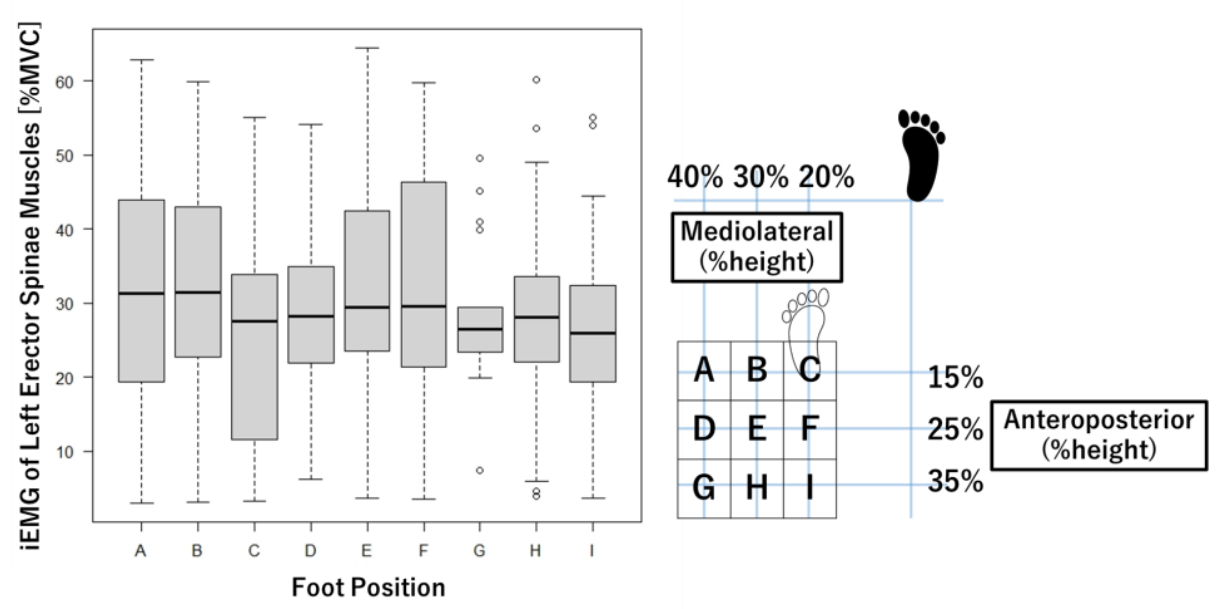

Fig. 7. iEMG of left erector spinae muscle of nine foot positions 


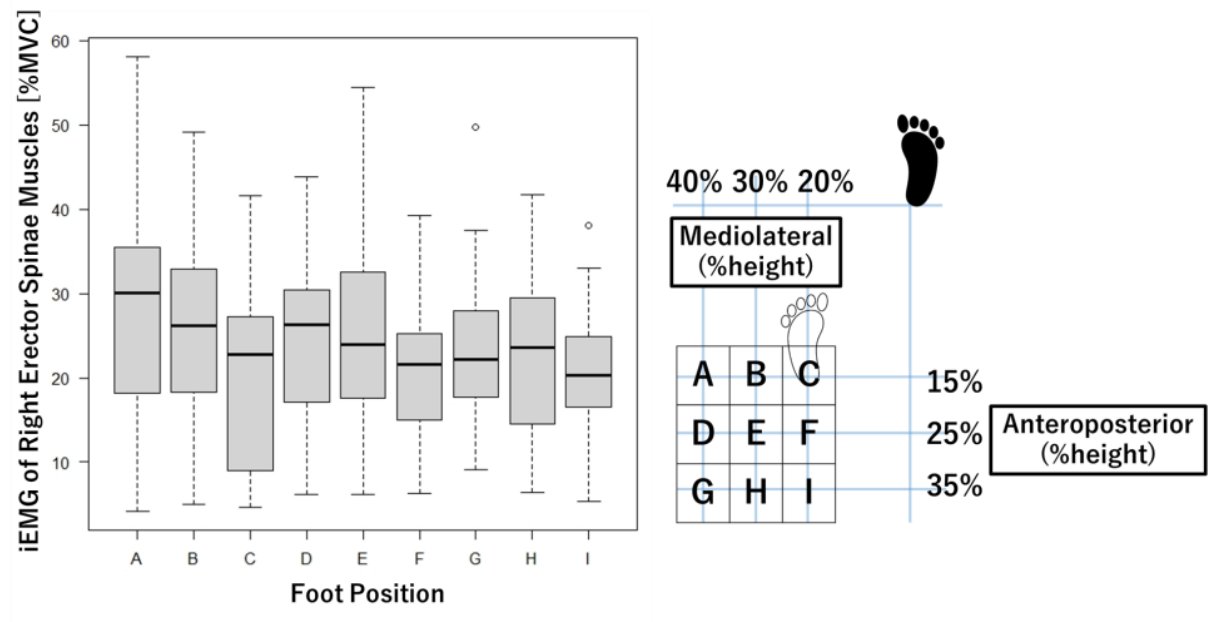

Fig. 8. iEMG of right erector spinae muscle of nine foot positions

\section{Discussion}

This study investigated the relationship between foot position and lumbar loads while turning patients on a bed.

The compression stress of L4-L5 values obtained from this study were comparable to previous studies related to turning patient on a bed $[6,9,10]$. Initial posture had the largest compression stress of L4-L5 in turning a patient on a bed. The reason for this trend is that the largest trunk flexion of initial posture caused the largest compression force of L4-L5. As shown in our previous study, the initial posture with the largest trunk flexion had the largest compression force in assistive sit-to-stand motion [13]. Additionally, in previous studies, it was reported that trunk flexion increased compression stress of the lumbar vertebrae $[37,38]$. Thus, caregivers should reduce trunk flexion of initial posture in turning patient on a bed.

The maximum value of compression stress of L4-L5 in foot positions A, B, and C with shorter anteroposterior foot distance was smaller than that of other foot positions. Additionally, the caregiver is close to the patient in foot positions $\mathrm{A}, \mathrm{B}$, and $\mathrm{C}$, and a significant correlation between maximum compression stress of L4-L5 and distance was noted between caregiver and patient. These results support our hypothesis that foot positions with short anteroposterior foot distance contribute to reducing lumbar loads due to closeness to the patient. Closeness to the patient is recommended by body mechanics for patient handling [7]. However, foot positions with long foot distance reduced lumbar loads in assistive sit-to-stand motion [13, 14]. This motion required using lower limb movement obtained from long anteroposterior foot distance instead of lumbar movement $[13,14]$. Turning a patient on a bed did not require using the lower limb; thus, a shorter anteroposterior foot distance is more suitable for turning the patient. 
The maximum compression stresses of L4-L5 in foot positions A, B, and C were smaller than $3400 \mathrm{~N}$ as injury shreshould. These findings suggest that foot positions $\mathrm{A}, \mathrm{B}$, and $\mathrm{C}$ are recommended for turning patient on a bed. Particularly, foot position A with a wide stance is the most suitable position for turning patients on a bed because a wide stance is recommended to obtain a base of support in body mechanics [7].

There was no difference in mean compression stresses of L4-L5 and iEMG of erector spinae muscle activity in the nine foot positions. These results revealed that foot position affected lumbar loads for only the initial posture of turning patient on a bed. Therefore, other postural parameters such as trunk movement should be optimized to reduce lumbar loads other than the initial posture.

There is one limitation to this study. The participants were only males without experience in patient handling. Movement and lumbar loads of manual handling were affected by previous experience, gender, or age [39]-[41]. Thus, the relationship between foot position and lumbar loads should be investigated for clinical field and experienced caregivers. Furthermore, because the 3DSSPP was not able to process inertial data, this study did not consider the velocity and acceleration of joint movement. Future works should prepare different musculoskeletal computational simulations that can process velocity and acceleration data of motion. For example, the AnyBody Modeling System (AnyBody Technology A/S, Denmark) can build a computational musculoskeletal model that processes inertial data [42, 43].

The feedback system will be proposed for foot position while turning patient on a bed and should be simple and easy to use because caregivers require time-efficient, comfortability, and cost effective assistive devices [11]. Wearble sensors for human motion measurement [44, 45] will be applied for this feedback system. In addition, suitable motion with optimal foot position will be implemented to caregivers via online learning tools for nursing education [46].

\section{Conclusion}

This study investigated the relationship between foot position and lumbar loads while turning a patient on a bed to prevent LBP among caregivers. The results showed that foot position with short anteroposterior foot distance could reduce the largest lumbar loads of initial posture because of closeness to a patient. These findings suggest that foot position with short anteroposterior foot distance is recommended to prevent LBP due to turning the patient on a bed. Future studies should propose implementation methods for the foot position to prevent LBP due to turning a patient on a bed.

\section{Acknowledgment}

The first author is grateful for a scholarship from the Nakatani Foundation for Advancement of Measuring Technologies in Biomedical Engineering. 


\section{$7 \quad$ References}

[1] Smedley, J., Egger, P., Cooper, C. and Coggon, D. (1995). Manual handling activities and risk of low back pain in nurses. Occupational and environmental medicine 52 160-3. https://doi.org/10.1136/oem.52.3.160

[2] Kitagawa, K., Nagasaki, T., Nakano, S., Hida, M., Okamatsu, S. and Wada, C. (2021). Analysis of Occupational Injury Reports Related to Patient Care Activities Using Text Mining Technique. In 11th Asian-Pacific Conference on Medical and Biological Engineering: Proceedings of the Online Conference APCMBE 2020, May 25-27, 2020. Springer Nature 82 153-8. https://doi.org/10.1007/978-3-030-66169-4_20

[3] Holtermann, A., Clausen, T., Jørgensen, M. B., Burdorf, A. and Andersen, L. L. (2013). Patient handling and risk for developing persistent low-back pain among female healthcare workers. Scandinavian journal of work, environment \& health 164-9. https://doi.org/ $10.5271 /$ sjweh.3329

[4] Kai, S. (2001). Consideration of low back pain in health and welfare workers. Journal of Physical Therapy Science 13 149-52.

[5] Wardell, H. (2007). Reduction of injuries associated with patient handling. Aaohn Journal 55 407-12. https://doi.org/10.1177/216507990705501003

[6] Schibye, B., Hansen, A. F., Hye-Knudsen, C. T., Essendrop, M., Böcher, M. and Skotte, J. (2003). Biomechanical analysis of the effect of changing patient-handling technique. Applied ergonomics 34 115-23. https://doi.org/10.1016/s0003-6870(03)00003-6

[7] Karahan, A. and Bayraktar, N. (2004). Determination of the usage of body mechanics in clinical settings and the occurrence of low back pain in nurses. International Journal of Nursing Studies 41 67-75. https://doi.org/10.1016/s0020-7489(03)00083-x

[8] Ibrahim, R. and Elsaay, O. (2015). The effect of body mechanics training program for in tensive care nurses in reducing low back pain. IOSR Journal of Nursing and Health Science 4 81-96.

[9] Wiggermann, N. (2016). Biomechanical evaluation of a bed feature to assist in turning and laterally repositioning patients. Human factors 58 748-57. https://doi.org/10.1177/ $\underline{0018720815612625}$

[10] Budarick, A. R., Lad, U. and Fischer, S. L. (2020). Can the use of turn-assist surfaces reduce the physical burden on caregivers when performing patient turning? Human factors 62 77-92. https://doi.org/10.1177/0018720819845746

[11] Sivakanthan, S., Blaauw, E., Greenhalgh, M., Koontz, A. M., Vegter, R. and Cooper, R. A. (2019). Person transfer assist systems: a literature review. Disability and Rehabilitation: Assistive Technology 1-10. https://doi.org/10.1080/17483107.2019.1673833

[12] Doss, R., Robathan, J., Abdel-Malek, D. and Holmes, M. W. (2018). Posture coaching and feedback during patient handling in a student nurse population. IISE Transactions on Occupational Ergonomics and Human Factors 6 116-27. https://doi.org/10.1080/24725838 .2018 .1428838

[13] Kitagawa, K., Nishisako, Y., Nagasaki, T., Nakano, S. and Wada, C. (2019). Musculoskeletal simulation of the relationship between foot position and stress of the L4-L5 joint in supporting standing-up motion to prevent low back pain among caregivers. Journal of $\mathrm{Me}$ chanics in Medicine and Biology 19 1940016. https://doi.org/10.1142/s0219519419400165

[14] Kitagawa, K., Nagasaki, T., Nakano, S., Hida, M., Okamatsu, S. and Wada, C. (2020). Optimal foot-position of caregiver based on muscle activity of lower back and lower limb while providing sit-to-stand support. Journal of Physical Therapy Science 32 534-40. https://doi.org/10.1589/jpts.32.534 
Paper - Relationship between Foot Position and Lumbar Loads while Turning Patient on a Bed...

[15] Yaqoob, S., Afzal, F. and Asim, H. M. To Check The Association Of MRI And Clinical Features In Patients With L4-L5 \& L5-S1 Disc Prolapse In Laborers.

[16] Genaidy, A. M., Waly, S. M., Khalil, T. M. and Hidalgo, J. (1993). Spinal com pression tolerance limits for the design of manual material handling operations in the workplace. Ergonomics 36 415-34. https://doi.org/10.1080/00140139308967899

[17] Potvin, J. R. (2008). Occupational spine biomechanics: a journey to the spinal fron tier. Journal of Electromyography and Kinesiology 18 891-9. https://doi.org/10.1016/j. jelekin.2008.07.004

[18] Bean, J. C., Chaffin, D. B. and Schultz, A. B. (1988). Biomechanical model calcu lation of muscle contraction forces: a double linear programming method. Journal of biomechanics 21 59-66. https://doi.org/10.1016/0021-9290(88)90192-3

[19] Rajaee, M. A., Arjmand, N., Shirazi-Adl, A., Plamondon, A. and Schmidt, H. (2015). Comparative evaluation of six quantitative lifting tools to estimate spine loads during static activities. Applied ergonomics 48 22-32. https://doi.org/10.1016/j.apergo.2014.11.002

[20] Nadon, A. L., Cudlip, A. C. and Dickerson, C. R. (2017). Joint moment loading interplay between the shoulders and the low back during patient handling in nurses. Occupational Ergonomics 13 81-90. https://doi.org/10.3233/oer-170256

[21] Iridiastadi, H., Vani, T. and Yamin, P. A. R. (2020). Biomechanical Evaluation of a Pa tient-Handling Technology Prototype. International Journal of Technology 11 180-9. https://doi.org/10.14716/ijtech.v11i1.1332

[22] Cooper, G. and Ghassemieh, E. (2007). Risk assessment of patient handling with ambulance stretcher systems (ramp/(winch), easi-loader, tail-lift) using biomechanical failure criteria. Medical engineering \& physics 29 775-87. https://doi.org/10.1016/j.medengphy .2006 .08 .008

[23] Adnan, N. M. N., Ab Patar, M. N. A., Lee, H., Yamamoto, S.-I., Jong-Young, L. and Mahmud, J. (2018). Biomechanical analysis using Kinovea for sports application. In IOP conference series: materials science and engineering vol 342 p 012097. IOP Publishing. https://doi.org/10.1088/1757-899x/342/1/012097

[24] Elwardany, S. H., Eleiny, K. E. A. and Arabia, S. (2015). Reliability of Kinovea com puter program in measuring cervical range of motion in sagittal plane. Open Access Library Journal 2 1. https://doi.org/10.4236/oalib.1101916

[25] Pueo, B., Penichet-Tomas, A. and Jimenez-Olmedo, J. M. (2020). Validity, reliability and usefulness of smartphone and kinovea motion analysis software for direct measurement of vertical jump height. Physiology \& Behavior 227 113144. https://doi.org/10.1016/j. physbeh.2020.113144

[26] Puig-Diví, A., Escalona-Marfil, C., Padullés-Riu, J. M., Busquets, A., Padullés-Chando, X. and Marcos-Ruiz, D. (2019). Validity and reliability of the Kinovea program in obtaining angles and distances using coordinates in 4 perspectives. PLOS One 14 e0216448. https://doi.org/10.1371/journal.pone.0216448

[27] Itami, K., Yasuda, T., Otsuki, Y., Ishibashi, M. and Maesako, T. (2010). De velopment of a checking system for body mechanics focusing on the angle of forward leaning during bedmaking. Educational technology research 33 63-71.

[28] Callaghan, J. P., Gunning, J. L. and McGill, S. M. (1998). The relationship between lumbar spine load and muscle activity during extensor exercises. Physical therapy 78 8-18. https://doi.org/10.1093/ptj/78.1.8

[29] Nelson, A., Lloyd, J. D., Menzel, N. and Gross, C. (2003). Preventing nursing back injuries: redesigning patient handling tasks. AAOHN journal 51 126-34. https://doi.org/10. $\underline{1177 / 216507990305100306}$ 
Paper - Relationship between Foot Position and Lumbar Loads while Turning Patient on a Bed...

[30] Shair, E. F., Ahmad, S. A., Marhaban, M. H., Mohd Tamrin, S. B. and Abdullah, A. R. (2017). EMG processing based measures of fatigue assessment during manual lifting. BioMed research international 2017. https://doi.org/10.1155/2017/3937254

[31] McGill, S. M. (1991). Electromyographic activity of the abdominal and low back muscu lature during the generation of isometric and dynamic axial trunk torque: implications for lumbar mechanics. Journal of orthopaedic research 9 91-103. https://doi.org/10.1002/ jor.1100090112

[32] De Looze, M. P., Zinzen, E., Caboor, D., Heyblom, P., Van Bree, E., Van Roy, P., Toussaint, H. M. and Clarijs, J. P. (1994). Effect of individually chosen bed-height adjustments on the low-back stress of nurses. Scandinavian journal of work, environment \& health 427-34. https://doi.org/10.5271/sjweh.1378

[33] Wiggermann, N., Smith, K. and Kumpar, D. (2017). What bed size does a patient need? The relationship between body mass index and space required to turn in bed. Nursing research 66 483. https://doi.org/10.1097/nnr.0000000000000242

[34] Hislop, H. J. (2007). Daniels and Worthingham's Muscle testing. Saunders/Elsevier.

[35] Kanda, Y. (2013). Investigation of the freely available easy-to-use software 'EZR' for med ical statistics. Bone marrow transplantation 48 452-8. https://doi.org/10.1038/bmt.2012. $\underline{244}$

[36] Waters, T., Garg, A. and Putz-Anderson, V. (1994). Applications manual for the revised NIOSH lifting equation [DHHS (NIOSH) Pub No. 94-110]. National Institute for Occupational Safety and Health Cincinnati, OH. https://doi.org/10.26616/nioshpub94110

[37] Hoogendoorn, W. E., Bongers, P. M., De Vet, H. C., Douwes, M., Koes, B. W., Miedema, M. C., Ariëns, G. A. and Bouter, L. M. (2000). Flexion and rotation of the trunk and lifting at work are risk factors for low back pain: results of a prospective cohort study. Spine 25 3087-92. https://doi.org/10.1097/00007632-200012010-00018

[38] Merryweather, A. S., Loertscher, M. C. and Bloswick, D. S. (2009). A revised back compressive force estimation model for ergonomic evaluation of lifting tasks. Work 34263 72. https://doi.org/10.3233/wor-2009-0924

[39] Lindbeck, L. and Kjellberg, K. (2001). Gender differences in lifting technique. Ergonom ics 44 202-14.

[40] Boocock, M. G., Mawston, G. A. and Taylor, S. (2015). Age-related differences do affect postural kinematics and joint kinetics during repetitive lifting. Clinical Biomechanics 30 136-43. https://doi.org/10.1016/j.clinbiomech.2014.12.010

[41] Gagnon, M. (2003). The efficacy of training for three manual handling strategies based on the observation of expert and novice workers. Clinical Biomechanics 18 601-11. https://doi.org/10.1016/s0268-0033(03)00076-7

[42] Damsgaard, M., Rasmussen, J., Christensen, S. T., Surma, E. and De Zee, M. (2006). Analysis of musculoskeletal systems in the AnyBody Modeling System. Simulation Modelling Practice and Theory 14 1100-11.https://doi.org/10.1016/j.simpat.2006.09.001

[43] Wagner, D. W., Reed, M. P. and Rasmussen, J. (2007). Assessing the importance of motion dynamics for ergonomic analysis of manual materials handling tasks using the AnyBody modeling system. SAE Transactions 2092-101. https://doi.org/10.4271/2007-01$\underline{2504}$

[44] Ferreira Geraldo, A.C., Maria Kuasne, A., Kurikic, H.U. and Marcelino, R. (2020). Proto type of Wearable Technology Applied to the Monitoring of the Vertebral Column. International Journal of Online \& Biomedical Engineering, 16 34-49. https://doi.org/10.3991/ijoe. $\underline{\mathrm{v} 16 \mathrm{i} 01.11816}$ 
Paper - Relationship between Foot Position and Lumbar Loads while Turning Patient on a Bed...

[45] Tu, Y., Liu, L., Li, M., Chen, P., and Mao, Y. (2018). A Review of Human Motion Monitor ing Methods using Wearable Sensors. International Journal of Online Engineering, 14 168-79.

[46] Bowtell, L., Moloney, C., Kist, A. A., Parker, V., Maxwell, A., and Reedy, N. (2012). Enhancing nursing education with remote access laboratories. International Journal of Online Engineering, 8 52-9. https://doi.org/10.3991/ijoe.v8is4.2279

\section{Authors}

Kodai Kitagawa received an M.Eng. degree at the Kyushu Institute of Technology, Japan, in 2019. He is currently a Ph.D. student at the Graduate School of Life Science and Systems Engineering, Kyushu Institute of Technology, Japan. His current research interests include biomedical engineering, physical therapy, wearable sensing, and occupational health. He is a member of the Engineering in Medicine and Biology Society of the Institute of Electrical and Electronics Engineers (IEEE EMBS), the Society of Physical Therapy Science (SPTS).

Kotaro Yamamoto received a B.Eng. degree at the Department of Mechanical and Control Engineering, Kyushu Institute of Technology, Kitakyushu, Japan, in 2021. His current interests include ergonomics, mechanical engineering, biomedical engineering, and biomechanics.

Chikamune Wada received a B.Eng. degree in Mechanical Engineering from the Osaka University, Japan, in 1990, and a Ph.D. degree in Biomedical Engineering from Hokkaido University, Japan, in 1996. From 1996 to 2001, he was an assistant professor of the Sensory Information Laboratory, Hokkaido University. In 2001, he became an associate professor of the Human-Function Substitution System Laboratory, Kyushu Institute of Technology. Since 2016, he has been a professor of the HumanFunction Substitution System Laboratory. His research interests include assistive technology, especially measuring human motion and informing disabled people of the necessary information to improve their quality of life (QOL). He is a senior member of the Institute of Electronics, Information and Communication Engineers (IEICE) and also a member of the Institute of Electrical and Electronics Engineers (IEEE).

Article submitted 2021-06-30. Resubmitted 2021-08-02. Final acceptance 2021-08-03. Final version published as submitted by the authors. 